\title{
We the public space. Strategies to deal with inequalities in order to achieve inclusive and sustainable urban environments
}

\author{
Luisa Bravo \\ City Space Architecture, Italy \\ luisa.bravo@cityspacearchitecture.org
}

At the Ninth session of the World Urban Forum, convened by UN-Habitat, the United Nations Human Settlements Programme, held on 7-13 February 2018 in Kuala Lumpur, City Space Architecture was selected to promote a networking event, which took place on Sunday February II at the Kuala Lumpur Convention Centre.

As coordinator of the networking event, I invited as speakers Mirko Guaralda (Queensland University of Technology, Australia), Hendrik Tieben (The Chinese University of Hong Kong, Hong Kong), Manfredo Manfredini (University of Auckland, New Zealand), Gregor Mews (Urban Synergies Group, Australia), Winyu Ardrugsa (Thammasat University, Thailand), Abner Manlapaz (Life Haven Independent Living, Philippines), Robert Wong (Hong Kong Sheng Kung Hui Welfare Council, Hong Kong), Katherine Kline (General Assembly of Partners - Older persons), Jarunee Pimonsathean (Thammasat University, Thailand) and Jackie Mostny (Kompas Strategy, USA). The networking event was intended to be an effective contribution to the discussion related to improvement of human health and well-being, overcoming discrimination and inequalities, thus giving rights to vulnerable community-groups. Those references are relevant both for the implementation of the New Urban Agenda and for the achievement of the Sustainable Development Goals. Human health and well-being are strongly related to public space and the way it is designed and managed. Nowadays we often record the increasingly privatisation of the public domain in direct and indirect ways; also, the lack of facilities to access, live and enjoy the public space often isolate communities, limiting their freedom to engage into the public sphere. We mainly refer to public space's cultural richness, identity and diversity, but in our contemporary times public space is dealing more and more with inequalities, poverty and conflicts. Public spaces are meant to be open, inclusive and democratic, but today we see physical, social and economic barriers that challenge the true nature of public space: economic issues, social and cultural segregation, huge real estate investments, privatization trends and gentrification processes are dominating aspirations of local communities and different social groups. We also experience theoretical barriers to an open discussion on public space: the discourse is often limited to specific national or linguistic areas and the dominance of exempla from the so-called global West or global North are limiting our knowledge about public space, often imposing an oversimplified view of public space design, management and use. Those 
barriers, physical and theoretical, are a threat to our communities in terms of access to basic needs; they are also an obstacle for the implementation of the New Urban Agenda and its principles.

The networking event briefly presented several researches and case studies intended to highlight strategies to deal with inequalities: I) accessibility and inclusiveness for people with physical or mental disabilities; 2) inclusiveness for children; 3) accessibility for older persons; 4) segregation of social groups, economic inequalities due to privatization and gentrification trends; 5) accessibility through adequate mobility; 6) intergenerational city. After that, all attendees, about 40 in total, were divided in several groups, in order to properly discuss the six topics. The discussion was extremely fruitful and was an opportunity to critically pinpoint issues that are usually taken for granted. All groups were asked to share outcomes of their discussion, to identify strategies that can meet the needs of different social clusters or strategies that can address multiple instances of inequalities at once. In the end we took a group picture!

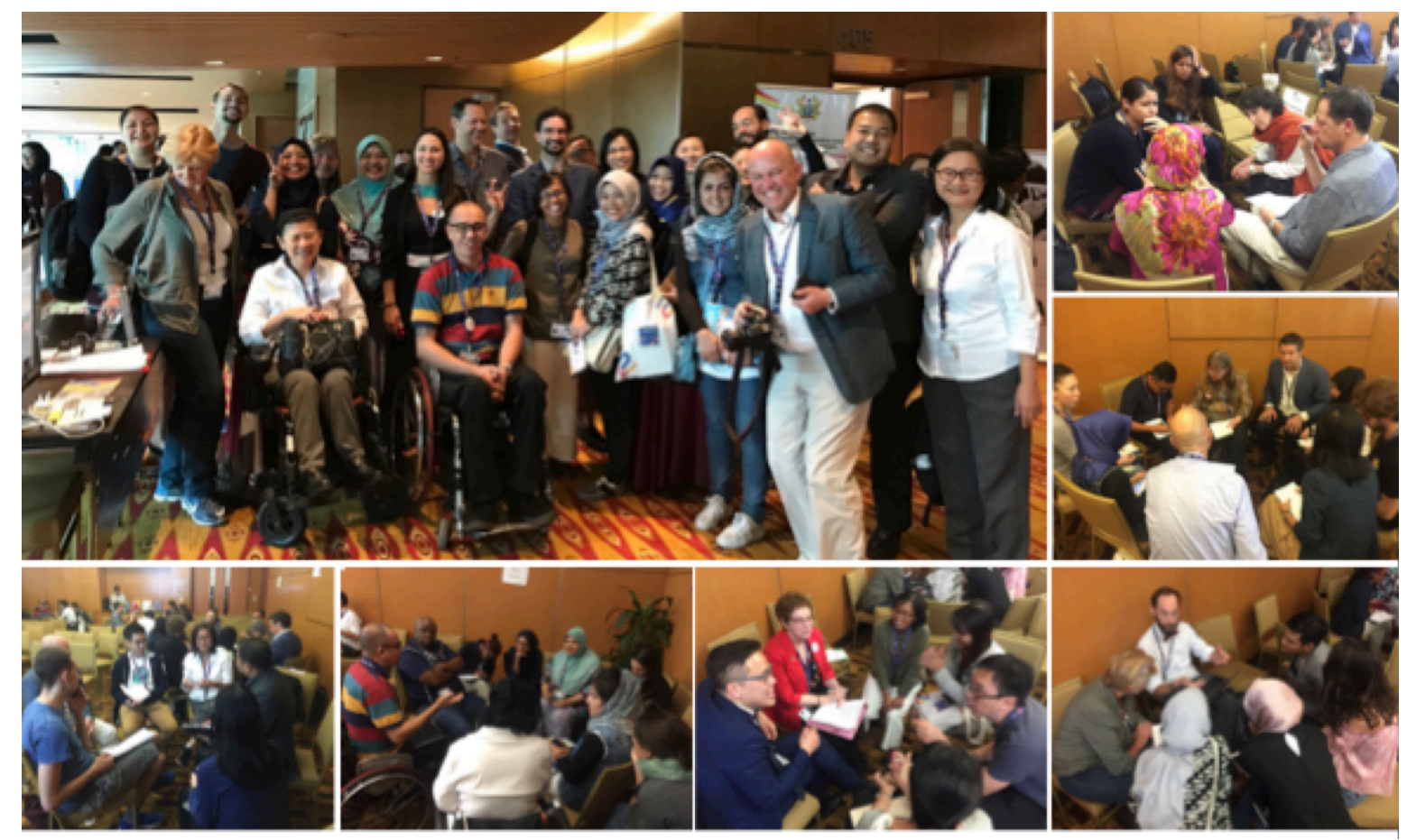

Fig. I. Group picture (top) at the end of the event and table discussions during the event.

\section{To cite this article:}

Bravo, L. (2018). We the public space. Strategies to deal with inequalities in order to achieve inclusive and sustainable urban environments. The Journal of Public Space, 3(I), I63-164. DOI: 10.5204/jps.v3il.326

This article has been accepted for publication in The Journal of Public Space. Please see the Editorial Policies under the 'About' section of the journal website for further information. 